\title{
El clown en la universidad argentina. La profesionalización de un oficio como parte de una metodología institucionalizada
}

\author{
Victoria Mercedes Cestau Yannicelli \\ UNTREF / Universidad de Buenos Aires \\ victoriacestau85@gmail.com
}

Fecha de recepción: 11/05/2018. Fecha de aceptación: 05/08/2018.

\begin{abstract}
Resumen
El clown es, en el campo teatral porteño, un oficio consolidado. Sin embargo, desde los estudios académicos no ha sido abordado desde el campo actoral. Los escasos estudios que existen aportan una mirada historiográfica, pero aún no problematizan el trabajo y la formación del actor. La llegada del clown y la formación en circo a la Universidad estatal argentina se hace inminente en el siglo XXI. Problematizaremos su introducción en el campo educativo a nivel universitario.
\end{abstract}

\section{The Clown at the Argentinian University: its Professionalization as Part of an Institutionalized Methodology}

Clown (as a specific, more theatrical, form of clowning, which is identified by the English denomination to distinguish it from the traditional payaso) is a consolidated line of artistic work in the theatrical field of Buenos Aires, Argentina. However, academic studies have not yet approached it from the acting perspective. The few existing studies provide a histographical overview, but still do not problematize the actor's work and training. Considering the arrival of Clown and formal training in circus arts becomes imminent at the Argentinian public university in the 21st Century, this essay problematizes its introduction in the educational field at the university level.

\section{Introducción y desarrollo del clown dentro del campo teatral porteño de los ochenta}

El clown es una metodología de actuación, que se inscribe dentro del teatro popular. Ha sido y es una novedosa y concurrida opción para muchos sujetos que deciden o no ser actores. La influencia y el aporte de la pedagogía lecoquiana en los años ochenta colaboraron a fortalecer y enriquecer una etapa de revalorización de las artes populares en la capital de nuestro país. En una primera etapa, la principal 
difusora del método de Lecog fue Cristina Moreira en los años 83 y 84; un año más tarde, Raquel Sokolowicz también se incorpora a la práctica docente de forma privada y personalista. El método desarrollado por Lecoq, difundido en su texto más conocido, El cuerpo poético (1997), sirvió para introducir la enseñanza sistematizada y contemporánea del clown. El maestro francés renueva y aporta una pedagogía que propicia y estimula la imaginación teatral de sus alumnos. Su pensamiento retoma las principales características del teatro popular que posiciona al actor como creador, donde principalmente se recupera su propio cuerpo.

Dentro del llamado teatro de la parodia y del cuestionamiento, en el marco de la periodización del teatro argentino (Pellettieri, 1992:36), se encuentra el clown que se caracterizó desde sus comienzos por su cuestionamiento al teatro serio y al ilusionismo propio del realismo dominante, al que se percibía como inactual durante los primeros años de la apertura democrática. Es un lenguaje teatral que se ha presentado exitosamente en el campo teatral porteño, luego de la dictadura militar, formando parte de la transición democrática de los ochenta, que rompía con las convenciones establecidas interpelando a los críticos, al público y a los teatristas del momento.

Parafraseando a Dubatti (1995: 15), a lo largo de la década se fue constituyendo de forma desordenada, en constante cambio, un renovador frente de artistas, de nuevos creadores, casi todos jóvenes, actores, directores, dramaturgos, que desarrollaron una estética teatral distinta, con respecto a las manifestadas durante la década de los sesenta. Esta estética emergente fue catalogada como teatro joven, teatro alternativo o teatro underground, un fenómeno que nacía al margen de los circuitos comerciales y oficiales, si bien, a medida en que tuvieron éxito entre el público y los críticos, fueron ganando posición en espacios comerciales y oficiales, así como también llegaron a la televisión.

Coincidimos con Pellettieri (1994) y Dubatti (1995: 29) en que este movimiento recuperó la estética del actor popular argentino, el circo y la murga. Expresó la voluntad de los nuevos realizadores de otorgar un estatuto teatral a fenómenos que hasta entonces eran considerados por la cultura alta como no teatrales. Asimismo, el fenómeno impactó también en la formación de los actores, poniendo de manifiesto que era posible otro cuerpo actoral, así como también que se volvía necesario recuperar la actuación y el teatro popular que caracterizó nuestro campo teatral desde sus inicios. Sin embargo, la inclusión de metodologías populares de actuación dentro de la enseñanza oficial universitaria es tardía, en comparación con la efervescente práctica teatral de los actores populares en distintos medios del campo cultural.

En su mayoría, los espectáculos de clown y de humor rompían con la cuarta pared integrando al público. La apropiación y utilización de la actuación improvisada en el escenario es el reflejo de una nueva necesidad dentro del campo teatral. No se limita a subrayar y celebrar la devaluación de la cultura escrita; todo lo contrario: propone una reflexión sobre las transformaciones que el nuevo paradigma está ejerciendo sobre el modo de percepción. La actuación deja de ser entendida en función de una narración con planteamiento, nudo y desenlace. El actor se presenta; él es el cuerpo, él es la actuación. El artista necesita y demanda del público una participación activa. La reapropiación del cuerpo del actor en escena es el reflejo de una necesidad de la sociedad por retomar los cuerpos callados, silenciados y desaparecidos del momento.

\section{La enseñanza del clown dentro del campo teatral porteño}

La enseñanza del clown, en nuestro campo teatral porteño, durante las tres décadas finales del siglo XX, estuvo fuertemente marcada por el desarrollo en formatos de talleres y seminarios intensivos de corte personalista y privado. Este formato de enseñanza y difusión 
de la metodología que nos ocupa abrió y expandió la posibilidad de formación que hasta entonces era imposible. Era un lenguaje novedoso para los artistas del momento, que encontraba una matriz común en los procedimientos y técnicas del mítico actor popular argentino. El clown lecoquiano, que se conformó y expandió durante los años ochenta, alimentó y resignificó al clown criollo local. Denominamos clown criollo a la variante que nace con la actuación de Pepe Podestá (1858-1937), que renovaba la habitual actuación de los clowns a la inglesa que actuaban para un público infantil. Podestá agregó la crítica y la sátira política: en este punto, el naciente clown criollo se comprometía con su realidad política y la parodiaba. Al respecto, Castagnino (1953: 80 y 81) explica que la aparición de un clown que rompía con toda una vieja tradición fue una verdadera revolución en los circos sudamericanos. En Europa, este aspecto de tradición popular fue retomado por Jacques Lecoq y Dario Fo y como crucial y como elemento perdido en la actualidad.

Siguiendo los estudios de Pellettieri (2001:15), el actor nacional es el intérprete de los géneros populares: gauchesca, nativismo, sainete, grotesco, vodevil, revista, originado en el circo criollo a partir de José Podestá. Son actores a los que, en su momento, la crítica conoció con el nombre de artistas menores, como actores cómicos, expulsados a los márgenes del campo intelectual.

Existe un recurso técnico común a todos los comediantes, es decir quienes trabajan específicamente el humor. Como los actores del Renacimiento que se apropiaban de las distintas problemáticas del lugar, y eran permeables a la cotidianidad de la sociedad. La empatía y el vínculo que generaban con el público reflejan el contacto directo con la realidad del pueblo, potenciado por la ruptura de la cuarta pared, que lo interpela directamente. Este aspecto es subrayado por Lecog (2009:147) como principio fundamental de la creación actoral que, más allá de los estilos o géneros, ya que se intenta enseñar el descubrimiento de los motores de la actuación específicos de cada territorio dramático. Es por esta razón que la creación debe estar enraizada siempre en el presente. El hecho de que la actuación popular rescate las problemáticas sociales, las manifieste arriba del escenario, las parodie y las emplee como material creativo para el actor es un patrón en común que se repite y que afianza un sentido materialista, comunitario y concreto del hecho teatral. Asimismo, refuerza a la actuación y al actor como protagonistas de la ficción junto al público.

\section{De las carpas tradicionales itinerantes a las escuelas establecidas}

En nuestro país, la primera escuela de circo la fundaron los Hermanos Videla en 1982 y la segunda fue fundada por Hochman en 1994. En 2010, la escuela de La Arena estableció un convenio con la Universidad de San Martín, por el que se creó el Programa de Formación Integral e Intensiva, de tres años de duración (Mogliani, 2017). En 1998, se creó el Circo Social del Sur fundado por Mariana Rúfolo y Pablo Holgado. Siguiendo los últimos estudios de Mogliani (2017) aparece en el 2000 la escuela de circo El Coreto, creada por Gabriela Ricardes y Mario Pérez.

La conocida EMAU (Escuela Municipal de Artes Urbanas de Rosario), creada en 2001, dependiente de la Secretaria de Cultura y Educación de la Municipalidad de Rosario, es otro proyecto que contempla y legitima la formación integral de jóvenes mayores de dieciséis y dieciocho años, ofreciendo dos carreras de tres y dos años de duración respectivamente: Intérprete en las Artes del Circo y Teatro Callejero. En la primera, las materias más relacionadas al arte del clown son mimo y comicidad. En la carrera de Teatro Callejero se busca fortalecer la formación teatral orientada al entrenamiento del actor para presentarse en espacios no convencionales. Todas estas formaciones contemplan al clown como un conocimiento necesario; sin embargo, la oferta educativa plantea un abordaje de aproximación y no de profundización. 


\section{El clown dentro de la universidad argentina. Los casos de la UNA, la UNSAM y la UNTREF}

La llegada del clown y la formación en circo a la universidad estatal argentina se hace inminente. El siglo XXI abre la necesidad de aprendizaje y perfeccionamiento de un saber legendario. La larga transformación social que ha sufrido el oficio del payaso ha estado influenciada por los cambios de producción en sus ámbitos laborales y de formación. De la carpa se pasa al teatro; de las compañías familiares e itinerantes, a las escuelas y talleres. A partir de la inserción de los sujetos en dichos espacios, el clown se va especializando de forma técnica. Al decir de Foucault (1985:144) las prácticas sociales que engendran dominios del saber no sólo hacen que aparezcan nuevos objetos, conceptos y técnicas, sino que suscitan el surgimiento de nuevos sujetos, en nuestro caso además implica el nacimiento de nuevos actores, de un nuevo teatro. El actor trabaja y se vincula con su realidad a través del cuerpo, herramienta fundamental para el hecho artístico. Controlar, vigilar y adiestrar las prácticas sociales desde los cuerpos de los individuos naturaliza y mantiene el orden que se quiere establecer. Una práctica como el clown que cuestiona el sistema y la lógica imperante es absorbida por la estructura que ordena. Desde este enfoque, problematizamos de qué forma y para qué se enseña clown en la universidad.

Se crean dos carreras universitarias legitimadas en el año 2009. Por un lado, la Universidad Nacional de San Martín (UNAS) ofrece la licenciatura en Artes Escénicas de cuatro años de duración, con un título intermedio alcanzado en el tercer año de Intérprete en Artes Escénicas. En relación a la enseñanza actoral, esta carrera propone dos materias, Actuación I y II, únicamente para la orientación denominada Artes Circenses. Por otro lado, la Universidad Nacional de Tres de Febrero (UNTREF) ofrece la Licenciatura de Intérprete de Circo, que es la única carrera universitaria estatal exclusivamente diseñada para el artista circense, de una duración de tres años y medio. El título que se otorga es el de Intérprete en Artes del Circo; las materias en relación a la formación actoral son Actuación I, II, y III cuya titular de la Cátedra es Cristina Moreira, la principal referente de este lenguaje. Dentro de las distintas cátedras de Actuación, con un criterio histórico correlativo (1800, hasta la actualidad), se plantean los distintos enfoques de las metodologías realistas y populares de actuación. Se abordan los principales maestros y movimientos teatrales, tanto desde el punto de vista teórico como práctico (se realizan distintas ejercitaciones), articulando dichos fenómenos artísticos con un pensamiento crítico provenientes de las ciencias sociales.

En la UNA, la Licenciatura en Actuación tiene dos seminarios optativos al final de la cursada. La profesora titular de los seminarios denominados "Clown" y "El Actor y el Clown" es Raquel Sokolowicz. En la Licenciatura en Composición Coreográfica con mención Danza-Teatro del Departamento de Artes del Movimiento, dictada por Cristina Moreira, se rinde la materia Clown en cualquier momento de la cursada. Es además materia optativa (también sin correlatividad) para las menciones Expresión Corporal y Comedia Musical en el mismo Departamento. A su vez, la UNA ofrece posgrados y talleres de otras metodologías de actuación popular como commedia dell' arte, bufón, máscaras balinesas, máscaras expresivas, máscara neutra. Dentro de la parte de extensión universitaria de la UNA se ofrece un taller de clown titulado Sembrando semillas rojas para adultos con y sin experiencia. Observamos cómo, desde la propia universidad, se ofrecen cursos de clown y de las restantes metodologías de actuación popular para sujetos sin experiencia; es decir, para sujetos que no son actores o para quienes les interesa la actuación de forma no profesional o como recurso técnico.

Observamos que la formación del artista nacional estuvo atravesada por varias tensiones. El campo educativo y más precisamente el actoral, desde mucho antes de establecerse como UNA, no ha contemplado las metodologías populares de actuación. 
La prioridad se la han otorgado al teatro textual y a la concepción stanislavskiana del actor. Esto actualmente está cambiando. Asistimos a una transición que, de a poco, construye un cambio de paradigma.

\section{La maestra del clown en Argentina.}

Cristina Moreira es la referente principal de esta metodología. No sólo reconocemos su figura que se destacó por el boom de aquellos años donde el clown que enseñó fue un éxito, sino que también se ha vuelto una especialista en enseñar otras metodologías de actuación popular muy necesarias para la formación de artistas, commedia dell' arte, bufón, vaudeville, burlesque y melodrama. Moreira integra varios lugares dentro del campo cultural/educativo. Es profesora, directora, dramaturga, investigadora y fue intérprete. La multiplicidad de espacios donde la maestra Moreira enseñó los seminarios intensivos en la década del '80 en Argentina, fueron centros y escuelas de formación privados e institucionales, la Escuela de Teatro de Mimo de Escobar y Lerchundi, maestros destacados y pioneros del mimo en el país. También en la escuela del Ballet de Danza Contemporánea del Teatro Municipal General San Martin y los espacios de extensión a la comunidad de la Escuela Superior de Danzas "María Ruanova", hoy Departamento de Artes del Movimiento de la UNA. La cátedra concursada de Clown que dicta la profesora Moreira en el DAM tiene como antecedente en la Universidad de las Artes la materia Clown en el programa de formación superior de Actor Nacional en el Conservatorio Nacional de Artes Dramáticas a partir del año 1996 actual Departamento de Artes Dramáticas de la U.N.A.

Actualmente, ejerce su labor docente en el ámbito universitario, donde también codirige y dirige distintos proyectos académicos, fue jurado nacional para la región centro como evaluadora de proyectos para el Instituto Nacional del Teatro durante los años 2016, 2017, 2018. En 2015, fue la responsable de generar un convenio entre La Asociación Civil Payamédicos y el Departamento de Artes del Movimiento. Dentro de la currícula de esta formación se incluyen textos en relación al clown y su impacto en el campo de la salud. Un año más tarde, se logró legitimar a través de la ley 14.726 la incorporación de los payasos de hospital dentro de la Provincia de Buenos Aires.

Moreira es profesora titular concursada de la asignatura de clown y profesora titular de la asignatura Técnicas de Circo de la carrera de Licenciatura en Composición Coreográfica con Mención Danza Teatro del Departamento de Artes del Movimiento del UNA. Ambas cátedras son pioneras en integrar al clown como metodología de actuación reconocida por la Universidad. Ha sido profesora de clown en el Conservatorio Nacional de Arte Dramático y ha dictado seminarios de clown en el Departamento de Artes Dramáticas del UNA. Profesora titular de Actuación I, II, III en la Carrera de Artes del Circo de la UNTREF.

\section{Algunas reflexiones finales}

Consideramos que el clown ha tenido éxito en nuestra capital ya que Buenos Aires presentaba un campo fértil de actores populares donde el clown lecoquiano reconoció una misma tradición actoral criolla.

Cristina Moreira construye su propia visión y pedagogía. Su aporte que hibrida escuelas, metodologías, autores y concepciones diversas ha enriquecido la enseñanza a través de sus libros y clases, tanto el ámbito público como privado.

La visita y el intercambio entre Moreira y el maestro Philippe Gaulier (principal discípulo de Jacques Lecoq) avalan la autonomización del clown y de todos los territorios 
dramáticos populares de actuación en relación a la pedagogía lecoquiana, dando origen a una nueva poética del clown en Buenos Aires. La invitación que Osvaldo Dragún le hace a Moreira, la posiciona y consolida como maestra y referente desde el ámbito oficial (Teatro Nacional Cervantes), legitimando su propio método de enseñanza. Su rol pedagógico alimenta a la revalorización de los géneros nacionales populares, donde también se consolida al nuevo circo. La participación de Moreira en la universidad como responsable de distintas cátedras y la invitación de Pellettieri para que se sume a la investigación académica fueron todos hitos que la consolidaron y posicionaron como la referente del clown y de otras metodologías populares de actuación.

Moreira ha impartido sus clases, en un primer tiempo de forma privada y personalista, donde construyó un lenguaje teatral que se desconocía y hasta se subestimaba dentro del campo teatral porteño de los ochenta. Más tarde, cuando el clown y las metodologías de actuación popular se fueron valorando y reconociendo, se posicionó dentro de una estructura mayor; tal es el caso de la universitaria, que responde a otros intereses.

La posición periférica del teatro y más aun de la actuación en el campo cultural porteño, queda manifiesta en el surgimiento tardío de instituciones de formación para actores. Así como al interior del campo actoral, aún hoy los actores cómicos o comediantes siguen considerándose "menos formados o menos cultos" que el resto. Las metodologías populares de actuación no tienen la misma valoración frente a otras metodologías en la formación de actores y artistas. El clown es una metodología de actuación que durante la formación universitaria, se encuentra débilmente presente en la currícula para los artistas. Es una opción que ha tenido mucho éxito para los sujetos que no son artistas y quieren incursionar en el mundo teatral. Estas dos variables han traído algunos problemas. En primer lugar, su presencia en la universidad debería construir una legitimación y sistematización de un saber complejo y antiguo. Esto no ocurre. Las pocas horas (no llega a contemplarse en la mayoría de los casos como materia de un cuatrimestre) que se ofrecen al alumnado desde la currícula oficial deterioran el nivel desde un espacio que se encuentra habilitado como un saber especializado, tal es el caso de la universidad. Esto genera una aproximación superficial a dicha metodología, debilitándola y alimentando los espacios privados y personalistas de educación, como maestros y escuelas privadas. En segundo lugar, el auge de talleres privados en el campo teatral porteño es controversial. Por un lado, seguimos alimentado la enseñanza no formal entre maestros y discípulos, que es y ha sido una de las formas más ricas del aprendizaje de este oficio, además de una de las formas de producción colectiva más importantes. Por otro lado, contribuye a que muchos sujetos, sin la preparación adecuada, comiencen a dar clases. Se ha naturalizado asistir a un par de talleres de clown y convertirse en profesor. También reconocemos grandes profesores y maestros que han difundido dicha metodología por el país de forma personal.

Como observamos, la oferta educativa en relación al clown es muy diversa y contempla tanto al ámbito formal público educativo como al informal privado. Las propuestas abarcan todos los niveles de enseñanza, tanto para niños y adolescentes como para adultos. La enseñanza del clown ha presentado en nuestro campo teatral la singularidad de nutrirse de otras disciplinas artísticas populares que se encontraban formando parte de una tradición local. La demanda educativa y la producción artística aumentan año tras año. La enseñanza del clown ha sido y es una salida laboral para muchos actores. La expansión educativa permitió la profesionalización de algunos artistas. Esto tiene dos consecuencias. La positiva es cada maestro le imprime características propias, enriqueciendo visiones y actualizándola. La consecuencia negativa es que, al haberse expandido de forma tan autodidacta, el clown implica de forma profunda al alumno y al maestro. Requiere un manejo del vínculo y de la transmisión de este 
saber que bordea aspectos psicológicos de ambas partes. De no saberse manejar pedagógica y didácticamente, se incurre en errores conceptuales y simplistas como un payaso debe hacer reir, buscando solamente el efecto sin comprender, ni desde la teoría ni desde la práctica, qué causa risa y para qué la utilizamos. El clown se difunde y se enseña dentro del campo educativo y teatral a personas sin experiencia desde distintos ámbitos legitimados como la universidad (en los formatos intensivos que brinda la UNA o en el Centro Cultural Ricardo Rojas de la Universidad de Buenos Aires) y privados personalistas (múltiples escuelas reconocidas.)

Uno de los aportes más importantes es que esta metodología ha sido enseñada a sujetos que no son actores. En tal caso sirve como herramienta técnica para fortalecer y enriquecer ciertos aspectos. Por ejemplo, estar más presentes en el aquí y ahora escénico, saber integrar al público durante la actuación, aprender algunas reglas de la improvisación, integrar los errores o accidentes a la actuación, saber entrary salir de la estructura que guía el espectáculo.

Dado las características propias de desarrollo, valorización y transmisión del clown en nuestro campo teatral porteño, consideramos que la influencia de la visión francesa traída por Moreira y Sokolowicz es innegable, así como también ambas maestras realizan sus propios aportes que contemplan mucho más que un modelo traído de afuera. No analizamos dicho fenómeno como un mero trasplante cultural. Todo lo contrario: al problematizar su autonomización en nuestra capital, consideramos por encima de todo que el teatro popular escapa a definiciones estancas. En la misma línea que sostenía Lecoq, consideramos incorrecta la lectura del teatro como un hecho puro. El teatro y las metodologías de actuación popular específicamente se relacionan con su contexto, con su público, alumnos y maestros de forma activa. Además de toda esa complejidad que atraviesa a cualquier fenómeno artístico, se integra la comicidad y el humor local, que fusionan siempre modelos tradicionales y modelos nuevos que constantemente se resignifican con la llegada de nuevas generaciones de artistas, críticos y espectadores.

El problema no reside en que nuestros países hayan cumplido mal y tarde un modelo de modernización que en Europa se habría realizado impecablemente, ni consiste tampoco en buscar reactivamente cómo inventar algún paradigma alternativo e independiente, con tradiciones que ya han sido transformadas por la expansión mundial del capitalismo, sobre todo, en el periodo más reciente, cuando la transnacionalización de la economía y de la cultura nos vuelve "contemporáneos de todos los hombres" (Paz) y sin embargo no se eliminan las tradiciones nacionales, optar en forma excluyente entre dependencia o nacionalismo, entre modernización o tradicionalidad local, es una simplificación insostenible (Canclini, 1990, p.80).

La práctica teatral es también un recurso para reconocer lo distinto y elaborar las tensiones de las diferencias. La hibridación de elementos técnicos y actorales que la metodología del clown utiliza es propia de una práctica cambiante y dinámica que, sin perder sus procedimientos típicos, los renueva. Coincidimos con el autor en concebir al campo educativo y cultural como espacios donde subyacen procesos de hibridación. Estas fusiones de disciplinas artísticas alimentan el desarrollo del clown y explican a su vez la diversidad de tipos de clown: clowns más musicales, clowns más parecidos a los mimos, clowns que optan por trabajar teatro de texto o autores clásicos, mal llamados clowns teatrales, y así todas las combinaciones posibles. Observamos también que ciertas herramientas del clown se encuentran aplicadas a otras disciplinas artísticas. 


\section{Bibliografía}

»Castagnino, R. H. (1953). El circo criollo. Buenos Aires: Lajouane.

" Castagnino, R. H. (1963). Sociología del Teatro Argentino. Buenos Aires: Nova.

"Castagnino, R. H. (1981). Circo, teatro gauchesco y tango. Buenos Aires: Instituto Nacional de Estudios de Teatro.

»Dubatti, J. (1995). Batato Barea y el nuevo teatro argentino. Buenos Aires: Planeta.

»Lecoq, J. (2009). El cuerpo poético, Alba, España.

» Fo, D. (1998). Manual mínimo del Actor. Buenos Aires: Hiru Hondabarria.

» Foucault, M. (1985). “Los cuerpos dóciles”. En Vigilar y castigar. Buenos Aires: Siglo XXI

" García Canclini, N. (1984). “¿De qué estamos hablando cuando hablamos de lo popular?”. En Punto de vista año VII, 20, mayo; 26-31.

» García Canclini, N. (1990). Culturas Híbridas. Estrategias para entrar y salir de la Modernidad. Buenos Aires: Paidós.

"Mogliani, L. (2007). Tesis de Doctorado: “El costumbrismo en el teatro argentino". Facultad de Filosofía y Letras de la Universidad de Buenos Aires (mimeo)

» Mogliani, L y Sanz, M. (2005) “Circo, títeres y volatineros." en: Osvaldo Pellettieri (director) Historia del teatro argentino en Buenos Aires, Vol. I, El periodo de la constitución (1700-1884), Buenos Aires: Galerna.

» Mogliani, L (2003). “Campo teatral. (1949-1960)", en: Osvaldo Pelletieri (director). Historia del Teatro Argentino. Volumen IV: La segunda modernidad (19491976), Buenos Aires; Galerna: 77, 90.

"Mogliani, L. (2017). Historia del Circo en Buenos Aires. De los volatineros a la formación universitaria. Catedra Historia del Circo. Carrera Artes del Circo. Universidad Nacional de Tres de Febrero.

》Moreira, C. (2008). Las múltiples caras del Actor, Buenos Aires: Inteatro,

" Moreira, C. (2015), Técnicas del clown, una propuesta emancipadora. Buenos Aires: Inteatro,

» Moreira, C. (2015). La commedia dell'arte. Un teatro de artesanos. Buenos Aires: Inteatro.

»Pellettieri, O. (2001). "En torno al actor nacional: el circo, el cómico italiano y el naturalismo". En Osvaldo Pelletieri (comp.) De Totó a Sandrini. Del cómico italiano al "actor nacional" argentino. Buenos Aires: Galerna.

»Pellettieri, O. (direc.), 2001, Historia del Teatro Argentino en Buenos Aires, Vol. V. Buenos Aires: Galerna. 